\title{
The competition with a concurrent cognitive task affects posturographic measures in patients with Parkinson disease
}

\author{
A competição com uma tarefa cognitiva afeta medidas posturográficas de pacientes com \\ doença de Parkinson \\ Alessandra Ferreira Barbosa ${ }^{1,2}$, Carolina de Oliveira Souza², Janini Chen², Débora Valente Francato², Fátima \\ Aparecida Caromano', Hsin Fen Chien², Egberto Reis Barbosa², Júlia Maria D’Andrea Greve, Mariana Callil Voos ${ }^{1,2}$
}

\begin{abstract}
Objectives: To estimate the impact of a sensory-motor- cognitive task on postural balance, in Parkinson disease patients (Hoehn and Yahr 2-3) and to investigate possible relationships between posturography and functional balance clinical scales. Method: Parkinson disease patients $(n=40)$ and healthy controls ( $n=27)$ were evaluated with fluency tests, Berg Balance scale, Mini Best test and static posturography on the conditions eyes open, eyes closed and dual-task (simultaneous balance and fluency tasks). Results: Posturographic data showed that Parkinson disease patients performed worse than controls in all evaluations. In general, balance on dual-task was significantly poorer than balance with eyes closed. Posturographic data were weakly correlated to clinical balance scales. Conclusion: In clinical practice, Parkinson disease patients are commonly assessed with eyes closed, to sensitize balance. Our study showed that adding a cognitive task is even more effective. Static posturographic data should be carefully overgeneralized to infer functional balance impairments.
\end{abstract}

Keywords: Parkinson disease, postural balance, cognition, aging.

RESUMO

Objetivos: Estimar o impacto de uma tarefa sensório-cognitivo-motora no equilíbrio, em pacientes com doença de Parkinson e investigar possiveis relações entre dados posturográficos e escalas de equilíbrio funcional. Método: Pacientes $(n=40)$ e controles $(n=27)$ foram avaliados com testes de fluência verbal, escala de equilíbrio de Berg (BBS), Mini Best Test (MBT) e posturografia estática nas condições olhos abertos, olhos fechados e tarefa-dupla (equilíbrio e fluência verbal, simultaneamente). Resultados: Dados posturográficos mostraram que pacientes apresentaram pior desempenho que controles em todas as avaliações. O equilíbrio na dupla-tarefa foi pior que na privação visual. Dados posturográficos apresentaram correlações fracas com a a BBS e MBT. Conclusão: Pacientes com Parkinson são comumente avaliados com olhos fechados para sensibilizar o equilíbrio. Nosso estudo mostra que a adição de uma tarefa cognitiva é mais efetiva. Dados da posturografia estática devem ser generalizados com cuidado nas interferências sobre equilíbrio.

Palavras-chave: doença de Parkinson, equilíbrio postural, cognição, envelhecimento.

Parkinson disease (PD) is a progressive degenerative disorder of the central nervous system, and affects 1.5 to $2.0 \%$ of the elder population (above 60 years of age) ${ }^{1}$. It is typically characterized by tremors, muscle rigidity, bradykinesia, diskinesia and loss of adaptive responses as muscle strength and aerobic capacity ${ }^{1,2}$. One of the most important disabilities that appear on the course of the disease is the postural instability, which is also one of the main challenges in PD rehabilitation $^{3,4}$. Recent studies have shown that non-motor disorders are also present in these patients ${ }^{1,5}$, e.g. humor, sleep, executive function, social behavior disorders ${ }^{6}$.

The mechanisms associated with postural instability are still not fully understood. Studies suggest that the dysfunctioning of the pedunculopontine nucleus, leads to the loss of anticipatory and compensatory postural responses automation, and disrupts sensory-motor integration (visual, proprioceptive and vestibular information processing and motor response selection) $)^{3,7,9}$. Postural control deficits enhance

\footnotetext{
1 Universidade de São Paulo, Faculdade de Medicina, Departamento de Fisioterapia, Fonoaudiologia e Terapia Ocupacional, São Paulo SP, Brazil; ${ }^{2}$ Universidade de São Paulo, Faculdade de Medicina, Departamento de Neurologia, Clínica de Distúrbios do Movimento. Grupo ReMove, Reabilitação em distúrbios do movimento, São Paulo SP, Brazil;

${ }^{3}$ Universidade de São Paulo, Faculdade de Medicina, Instituto de Ortopedia e Traumatologia, Hospital das Clínicas, São Paulo, SP, Brazil. Correspondence: Alessandra Ferreira Barbosa; Rua Capote Valente, 395 / apto 12; 05409-001 São Paulo SP, Brasil; E-mail: alefbar@gmail.com Conflict of interest: There is no conflict of interest to declare.

Received 01 May 2015; Received in final form 19 July 2015; Accepted 12 August 2015.
} 
trunk and knees flexion and increase the need for attentional control over posture ${ }^{4}$. Postural instability is a major cause of disability in these patients, exposing them to increased fall risk, insecurity and restrictions on movement and daily life activities ${ }^{10}$.

Similarly, cognitive deficits, specifically in executive functions, can significantly affect functional independence and compromise security. Executive function is a broad concept that includes the ability to monitor and process internal and external information, attend to multiple tasks concurrently, set and achieve goals, solve problems, and regulate environmental demands. As PD progresses, the executive function and postural control deteriorate and the degree of cognitivemotor dependency increases ${ }^{11,12}$.

Diverse tools as Timed up and Go test (TUG), Berg Balance Scale (BBS), Six-Minute Walk Test, Dynamic Gait Index and, more recently, MiniBest test $(\mathrm{MBT})^{11}$ evaluate postural control in PD patients. Beyond these clinical assessments, the gold-standard evaluation of postural control is the computerized posturography. This kinetic evaluation measures the center of pressure oscillation in order to assess the efficiency of postural control adjustments ${ }^{13}$.

Although many authors have used this tool to evaluate the postural instability of patients with PD, the results are still inconclusive ${ }^{14}$. Furthermore, variations in the adopted methods and variables make it difficult to compare studies. Ickenstein et al. ${ }^{7}$ studied a methodology that could differentiate patients with PD from healthy controls. The chosen task was an adapted version of Romberg test in two conditions, eyes open and eyes closed, evaluated by variables drawn from the oscillation trajectory. This method was able to differentiate the two groups, especially in visual deprivation.

Johnson et al. ${ }^{14}$ aimed to differentiate PD patients with falls history from more stable patients and healthy controls using a combination of clinical tests and static posturography. Area oscillation measurement differentiated healthy controls from PD patients with falls history. The study also found positive correlations between BBS, TUG and oscillation area. The reaction time was an important variable to distinguish the three groups; this variable was related to cognitive processing. Cognitive tasks, when associated with motor tasks, cause major disturbance in PD patients. Such negative cognitive-motor interaction is documented in balance and gait in PD patients ${ }^{15,16,17,18}$.

Many studies have found the effect of sensory disturbance in static balance, but few evaluated the cognitive task addition effect. Marchese et al. ${ }^{3}$ evaluated the static posturography in patients with PD and age matched controls in static posturography conditions, associated with a simple motor task, and a cognitive task, with and without visual deprivation. They found greater disturbance on balance during the association of the cognitive task and no effect regardless of visual condition.
Despite the different methodologies employed, the latest results point to the worsening of postural control in conditions of sensory disturbance, and in association with cognitive tasks, poorly described for static postural control. However, studies fail to clarify whether the static posturography would be an effective tool for clinical assessment and whether it could be related to clinical balance assessment.

The aim of this study was to investigate whether the association of a cognitive task would affect postural control in patients with PD in the same way that visual deprivation. The secondary objective was to investigate a possible relationship between the static posturography data and clinical balance scales.

\section{METHOD}

\section{Subjects}

This study was approved by the Ethics committee on research at the University of São Paulo Clinics Hospital in accordance with the Declaration of the World Medical Association. All participants read and signed a written informed consent approved by this committee. Fifty-nine healthy elderlies from a senior center of the University of São Paulo Clinics Hospital were invited to participate in the control group. Thirty-five volunteered and twenty-seven met the inclusion criteria, gave informed consent and underwent sensory-cognitivemotor assessment protocol.

For both control and experimental groups, only people aged between 60 and 79 years, with 5 or more years of formal education and with a minimal Mini-mental score of $24^{19}$, according to the cut-off determined by the Brazilian version of the test, were included. Subjects with acute or terminal illnesses, myocardial infarction in the last six months, moderate or severe chronic obstructive pulmonary disease, uncontrolled hypertension, uncontrolled metabolic disease, acute orthopedic injuries, and other neurological and/or muscular disease were excluded from the study.

Seventy-eight outpatients with idiopathic PD, from the Movement Disorders Clinic of the University of São Paulo Clinics Hospital were invited to participate in the experimental group. Fifty-two volunteered and forty met our inclusion criteria and gave informed consent. Additional inclusion criteria for PD patients comprehended having received the diagnosis of PD according to the clinical criteria of the United Kingdom Parkinson Disease Society Brain Bank ${ }^{20}$; Hoehn and Yahr $^{21}$ (H\&Y) score between 2 and 3; being on antiparkinsonian drug treatment at a stable and optimized daily dosage during the last 4 weeks prior to study entry.

\section{Procedures}

Participants were assessed individually, on one session. After receiving detailed explanation about the study, they signed the informed consent. Both groups were assessed with 
the Mini-Mental State Examination (MMSE), fluency tests (animals: saying animals names and phonemic: saying words beginning with letter F), BBS, MBT and static posturography. Patients with PD were on their best "on" state.

\section{Cognitive assessment}

All participants underwent cognitive assessment comfortably seated on a chair placed in front of a table. The MMSE screened for severe cognitive impairment and only subjects scoring above 24 points were included ${ }^{19}$. In the fluency test, subjects were instructed to say as many as animals as they could remember in one minute, without repetition or gender changing. Each word was scored with one point and repeated words were not scored, this test has been found to be a predictor of latter development of dementia ${ }^{22}$.

\section{Motor assessment}

The BBS is a widely-used measure of balance and has been validated for PD patients. It consists of a 14-item scale, scored from zero to four (best), assessing abilities involving sitting, standing and positional changes ${ }^{23}$. The MBT is a more recent tool developed to assess balance. It involves four domains: anticipatory, sensory, gait and reactive and totalizes 14 items, scored from 0 to 2 (best performance). It has a high correlation with BBS, but the combination BBS-MBT reduces the ceiling effect of higher scored patients ${ }^{24}$.

\section{Sensory-cognitive-motor assessment}

Participants stood barefoot on a 0.5 X $0.5 \mathrm{~m}$ platform (AMTI Accusway Plus; Advanced Mechanical Technology, Inc., Watertown, Massachusetts, USA) with their arms alongside the body and their feet $5 \mathrm{~cm}$ apart. Feet positions were marked and kept the same in all trials. The frequency of acquisition was set up at $100 \mathrm{~Hz}$.

Data were collected in three trials of 60 seconds, under three conditions: (i) keeping balance with eyes open (EO); (ii) keeping balance with eyes closed (EC); (iii) dual-task (DT): keeping balance with eyes open and performing three fluency tasks: saying as many words as possible starting with letter F (trial 1), saying words starting with letter P (trial 2) and naming fruits (trial 3). Each trial lasted for one minute.

Descriptive measures of the center of pressure (COP) displacement oscillation were collected by posturography: the mean velocity of the COP oscillation (Vavg), the elliptical area covering $95 \%$ of the COP projection points (area) and the standard deviations of the COP oscillation on both axes, mediolateral (SD-ML) and anteroposterior (SD-AP).

Rocchi et al. ${ }^{13}$ analysed fourteen variables related to the COP and concluded that standard deviation and mean velocity, provided insights about the postural control mechanisms and described changes in postural strategies. The area was chosen for being widely used in other posturography studies.

\section{Statistical analysis}

Data with normal distribution were expressed as means \pm standard deviations (SD). The level of significance was set at alfa $<0.05$. Student tests $t$ were used to compare the groups in terms of age, height, weight and number of years of formal education. Qui-square tests investigated sex distribution differences.

Analyses of Variance (ANOVAs) were performed to compare both groups and the three evaluation conditions on the posturography (eyes open, eyes closed, dual-task) as dependent variables. When a significantly interaction was found, Tukey post hoc tests were performed to complement the analysis. Additionally, Spearman correlation tests compared the performance on the balance clinical scales with the results of the posturographic evaluation.

\section{RESULTS}

\section{Clinical Data}

Table 1 shows demographic data and test scores for patients with PD and healthy controls. No significant differences were found in age, education, gender, height, weight and cognitive screening.

\section{Cognitive assessment}

The fluency test naming animals found significant difference between groups $(p=0.001)$. PD patients said significantly fewer words than the control group.

\section{Motor assessment}

Both clinical assessment tests, BBS and MBT, were sensitive in discriminating the PD group from control group, with poorer performances of PD patients $(p=0.007$ and $\mathrm{p}<0.001$, respectively).

Table 1. Demographic data for patients with PD and healthy controls.

\begin{tabular}{lccc}
\hline Groups & PD & Controls & P \\
\hline Age (years) & $67.17 \pm 4.3$ & $68.37 \pm 3.7$ & 0.115 \\
Education (years) & $9.77 \pm 4.87$ & $11.15 \pm 4.53$ & 0.121 \\
Gender (F/M) & $16 / 24$ & $17 / 10$ & 0.349 \\
Mean height & $1.65 \pm 0.09$ & $1.61 \pm 0.08$ & 0.603 \\
Mean weight & $70.5 \pm 12.96$ & $69.8 \pm 7.26$ & 0.391 \\
Mini-mental score & $27.7 \pm 2.09$ & $28.07 \pm 1.07$ & 0.340 \\
\hline *P
\end{tabular}




\section{Sensory-cognitive-motor assessment}

Mean velocity: ANOVA showed that the mean velocity of the COP oscillation (Vavg) was significantly different between groups $(p=0.020)$ and conditions $(p<0.001)$, but no interaction groups vs. conditions was found $(p=0.894)$ (Figure 1). For both groups, the velocity of body sway and the data confidence interval (data variability) gradually increased from eyes open to eyes closed conditions and from eyes closed to dual-task.

Elliptical area: The elliptical area covering $95 \%$ of the $\mathrm{COP}$ projection points and the standard deviation of the COP oscillation on mediolateral axis showed similar variations on the three conditions. Significant differences were observed between groups $(p=0.010)$ and conditions $(p<0.001)$, but no interaction groups vs. conditions ( $\mathrm{p}=0.771$ ) (Figure 2). Both groups had greater postural sway on the dual-task condition, comparing it to the conditions eyes open and eyes closed.

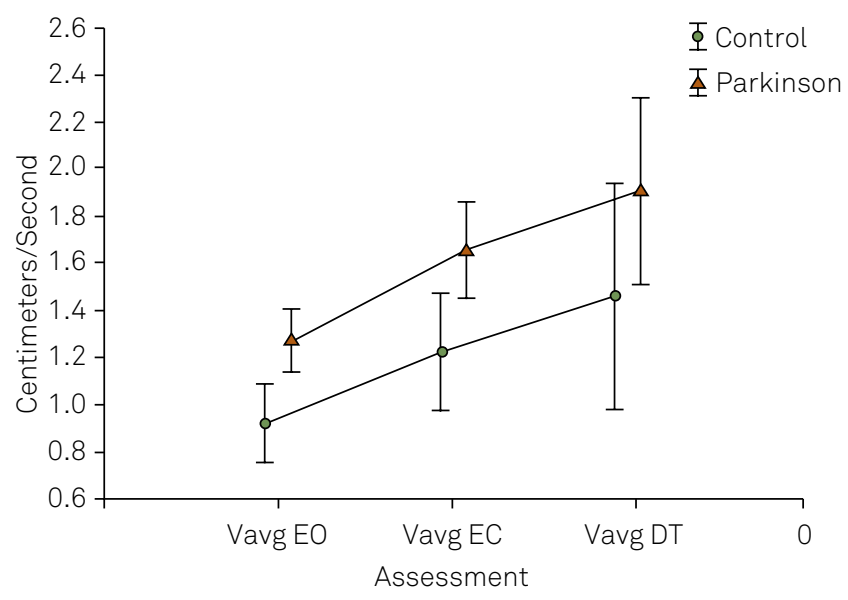

EO: eyes open, EC: eyes closed, DT: dual-task.

Figure 1. Performance of the groups in the three conditions for the mean velocity of oscillation (Vavg).

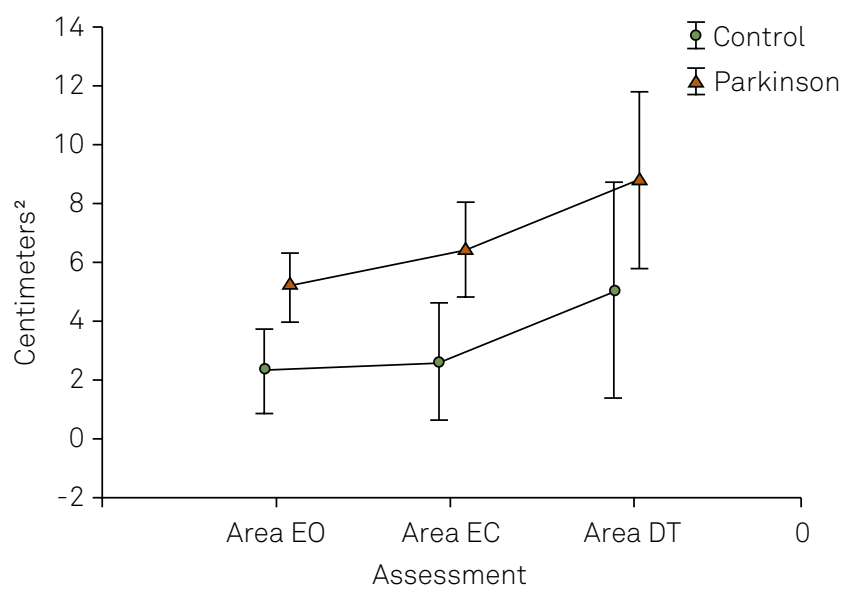

EO: eyes open, EC: eyes closed, DT: dual-task.

Figure 2. Performance of the groups in the three conditions for the elliptical area covering $95 \%$ of the trajectory points.
The addition of the cognitive task had more impact on postural control than the visual deprivation for both groups. A higher variability in performance (a higher confidence interval) was observed on dual-task conditions.

Standard deviation of the COP oscillation on mediolateral axis: The standard deviation of the COP oscillation on mediolateral axis (SD-ML) also showed a significant difference between groups $(\mathrm{p}=0.001)$ and conditions $(\mathrm{p}<0.001)$, but no interaction groups vs. conditions $(p=0.834)$ (Figure 3$)$. Both groups had greater postural sway on the dual-task condition, comparing it to the conditions eyes open and eyes closed. The addition of the cognitive task had more impact on postural control than the visual deprivation for both groups. A higher variability in performance (a higher confidence interval) was observed on dual-task conditions.

Standard deviation of the COP oscillation on anteroposterior axis: The standard deviation of the COP oscillation on anteroposterior axis (AP-SD) showed a significant difference between groups $(p=0.007)$, conditions $(p<0.001)$, and also a significant interaction groups vs. conditions $(\mathrm{p}=$ 0.027). PD patients showed a higher SD-AP during the whole assessment, while controls gradually increased their SD-AP on the conditions eyes closed ( $p=0.0005)$ and dual-task $(\mathrm{p}<$ 0.0001) (Figure 4).

\section{Relationship between clinical tests and posturography}

Spearman correlation tests were performed with the the PD group data. Possible relationships between the posturographic variables, the BBS and the MBT were investigated. The results are displayed in Table 2. For the control group, a weak correlation between SD-ML and MBT was found. Also, a moderate correlation between Vavg and BBS, in eyes open condition was found. For PD group there was only a weak correlation between SD-ML and BBS in eyes open condition (Table 2).

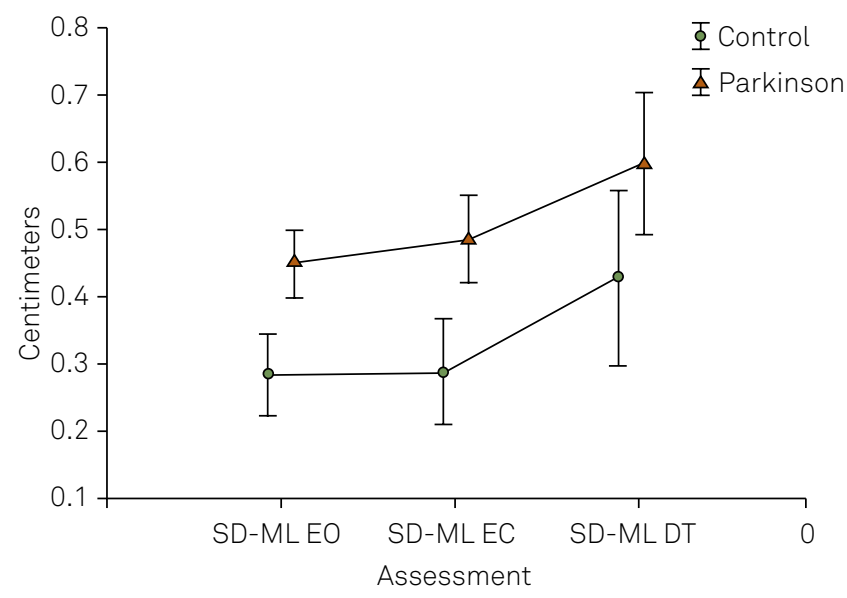

EO: eyes open, EC: eyes closed, DT: dual-task.

Figure 3. Performance of the groups in the three conditions for the mediolateral standard deviation (SD-ML). 


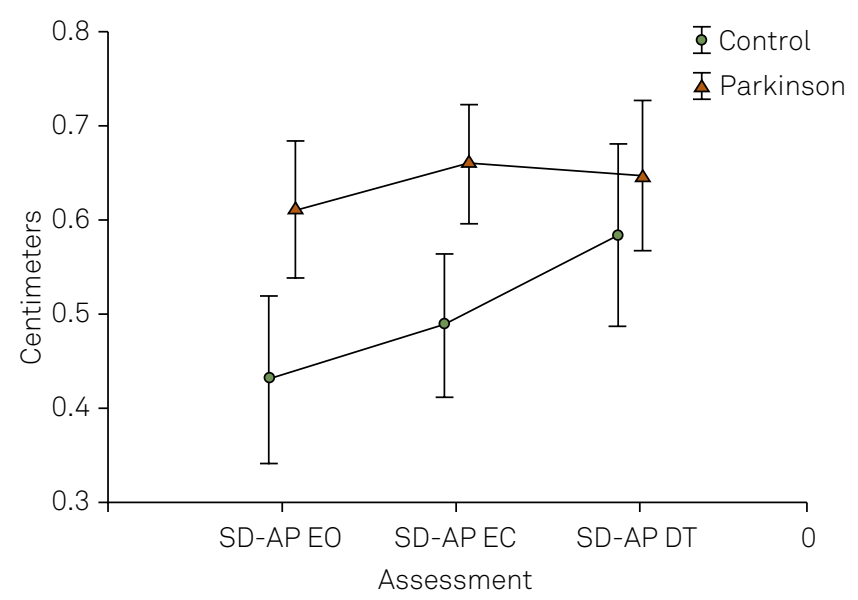

EO: eyes open, EC: eyes closed, DT: dual-task.

Figure 4. Performance of the groups in the three conditions for the anteroposterior standard deviation (SD-AP).

\section{DISCUSSION}

The present study investigated whether the association of a cognitive task would affect postural control in patients with PD in the same way that visual deprivation. Distinct modifications of posturographic data on the conditions eyes open, eyes closed and dual-task were found. Some differences between the experimental PD group and the control group were also observed.

It is well known that physiological aging impairs the processing of visual, vestibular and somatosensory information, which may also affect the postural control ${ }^{25}$. Healthy older people tend to rely more on visual information than on somatosensory information and, in cases of sensory conflict, they can present difficulty using vestibular information for postural control ${ }^{25}$. In the present study, PD patients presented a similar behavior as showed by Lee et al. ${ }^{8}$, about PD patients dependence on vestibular information. The authors hypothesized, in agreement with Yen et al. ${ }^{4}$, that balance impairments were associated with deficits in sensory processing and/or in the central integration of sensory information.

Beyond this natural aging process, other factors may contribute to balance disruption facing sensory disturbance, in this population. Loss of automation in performing postural changes can increase the dependence on visual information $^{26}$. Studies of Ickenstein et $\mathrm{al}^{7}$. and Rossi et $\mathrm{al}^{27}$. pointed to the increase of visual dependence, as a compensation mechanism, and explained that the overload of the visual system can affect postural control, as detected by posturography.

Changes on postural control due to sensory disturbance have been well described, such as changes on gait parameters in dual-task conditions, for both healthy elderly and PD patients ${ }^{16,17}$. However, our results add interesting data, because they showed that the competition with a concurrent cognitive activity disrupted posturographic measures in a different manner than visual deprivation.

For both groups, the elliptical area and the SD-ML did not change significantly on eyes closed condition, compared to eyes open condition, but they increased on dual-task, compared to eyes closed. For the dual-task condition Marchese et al. ${ }^{3}$ showed that the elliptical area was different in PD patients. The amount of compensatory stabilizing movements in both planes, needed by PD patients to maintain balance was higher. However, Brown et al. ${ }^{28}$ showed that, despite PD patients present deficit reorganizing the oscillation area after visual deprivation, this condition tends to stabilize after a period of time, which probably occurred in our sample with both variables (SD-ML and elliptical area).

The velocity of body sway increased with eyes closed, compared to the eyes open condition and on dual-task, compared to eyes closed. No other studies investigating the velocity of body sway with eyes open, closed and dual-task were found. However, Rocchi et al. ${ }^{13}$ reported a correlation between the velocity and the items related to tremor from the Unified Parkinson Disease Rating Scale. Therefore, it was expected that the PD group would show greater speed

Table 2. Relationships between posturographic and clinical data for patients with Parkinson disease (PD).

\begin{tabular}{|c|c|c|c|c|c|}
\hline & & \multicolumn{2}{|c|}{ Control } & \multicolumn{2}{|c|}{ PD } \\
\hline & & MBT & BBS & MBT & BBS \\
\hline \multirow[t]{4}{*}{ EO } & SD-ML & -0.142 & 0.074 & -0.223 & -0.338 \\
\hline & SD-AP & -0.074 & 0.232 & 0.207 & 0.114 \\
\hline & Vavg & 0.003 & -0.241 & -0.078 & -0.005 \\
\hline & Area & -0.062 & 0.210 & -0.039 & -0.171 \\
\hline \multirow[t]{4}{*}{ EC } & SD-ML & -0.388 & -0.229 & -0.121 & -0.242 \\
\hline & SD-AP & -0.087 & 0.101 & 0.305 & 0.168 \\
\hline & Vavg & -0.084 & -0.459 & 0.112 & 0.092 \\
\hline & Area & -0.320 & -0.130 & -0.004 & -0.146 \\
\hline \multirow[t]{4}{*}{ DT } & SD-ML & -0.297 & -0.169 & -0.098 & -0.160 \\
\hline & SD-AP & -0.042 & 0.236 & 0.194 & 0.065 \\
\hline & Vavg & -0.103 & -0.273 & 0.032 & 0.101 \\
\hline & Area & -0.238 & 0.027 & -0.002 & -0.107 \\
\hline
\end{tabular}

MBT: MiniBest test; BBS: Berg balance scale, EO: eyes open; EC: eyes closed; DT: dual-task condition; SD-ML: mediolateral standard deviation; SD-AP: anteroposterior standard deviation; Vavg: average velocity off oscillation; Area: elliptical area covering 95\% off trajectory oscillation. 
oscillation in all conditions, increasing according to the difficulty of the task, as well as the control group.

The groups showed distinct reactions on anteroposterior sway assessment. PD patients showed higher anteroposterior sway on all conditions, while controls showed gradual anteroposterior sway increase with eyes closed, compared to eyes open and on dual-task, compared to eyes closed. In the literature, no results like these were found, but we hypothesized that this finding might be attributed to a ceiling effect. On the sample of the present study, patients had higher variation in postural oscillation, which refers to the level of stability. Therefore, PD patients were less able than the control group to adapt to all conditions. This variable may be useful distinguishing PD and control groups, but not to evaluate the effects of a disturbance in postural control for PD patients.

Our results corroborate with the ones from Marchese et al. ${ }^{3}$, who noticed the worsening on postural sway (area, path lengthand mean velocity), during a cognitive task. In their study, they describe that the PD group and the control group were even more different when the PD group was divided considering the falls history. They pointed as possible causes for their findings the reduction of atentional capacity, a longer established balance deficit and the great resources competition for planning and production of the appropriate motor response. Considering these results, it is possible to conclude that static posturography alterations on dual-task conditions can show a major problem for the central processing and motor planning, thus detecting the PD patients with a higher risk of falling.

It was also investigated possible relationships between static posturography data and clinical functional balance assessment.

For healthy elderlies, in eyes closed condition, a weak correlation between SD-ML and MBT and a moderate correlation between Vavg and BBS were observed. For PD group, there was only a weak correlation in eyes open condition between SD-ML and BBS. As there were few correlations between posturographic variables and clinical scales and such relationships have not been fully investigated, it is recommended that the interpretation of posturographic data for clinical practice should avoid overgeneralization.

The application of the two scales showed great differences between the two groups, with a significant worsening of balance in the PD group. This was due to the fact that both scales evaluated more dynamic conditions, such as transferring and keeping a decreased base of balance. Lee et al. ${ }^{8}$ found strong correlations between cognitive tasks and balance on more challenging situations, indicating that the integrity of executive functions is important for planning adjustments to maintain the posture. Future studies should investigate whether the training of static balance associated with cognitive demands could be effective decreasing postural sway on dual-task, similar to that observed on gait training.

In clinical evaluation of neurological patients, it is common to ask patients to close their eyes in order to sensitize postural control and highlight balance disorders. Our results indicate that in dual-task (cognitive-motor) conditions the change in postural control can be even greater than with visual deprivation. This interaction can be greater in individuals with more evident balance disorders, with falls history.

Postural change in such cases show the physicians and therapists greater need for attention and balance training activities with varying degrees of difficulty, including the maintenance of static posture on dual-task conditions. As we found weak/ moderate correlations between posturography and clinical balance scales, data generalization should be done carefully. It is suggested that further studies are conducted, including posturography in dynamic conditions, to clarify this relationship.
1. Brienesse LA., Emerson MN. Effects of resistance training for people with Parkinson's disease: a systematic review. J Am Med Dir Assoc. 2013;14(4):236-41. doi:10.1016/j.jamda.2012.11.012

2. Kolk N., King L. Effects of exercise on mobility in people with Parkinson's disease. Mov Disord. 2013;28(11):1587-96. doi:10.1002/mds.25658

3. Marchese R, Bove M, Abbruzzese G. Effect of cognitive and motor tasks on postural stability in Parkinson's disease: a posturographic study. Mov Disord. 2003;18(6):652-8. doi:10.1002/mds.10418

4. Yen CY, Lin KH, Hu MH, Wu RM, Lu TW, Lin CH. Effects of virtual reality-augmented balance training on sensory organization and attentional demand for postural control in people with Parkinson disease: a randomized controlled trial. Phys Ther. 2011;91(6):862-74. doi:10.2522/ptj.20100050

5. Cruise KE, Bucks RS, Loftus AM, Newton RU, Pegoraro R, Thomas MG. Exercise and Parkinson's: benefits for cognition and quality of life. Acta Neurol Scand. 2011;123(1):13-9. doi:10.1111/j.1600-0404.2010.01338.x

6. Reijnders JSM, Ehrt.U, Lousberg R, Aarsland D, Leentjens AFG. The association between motor subtypes and psychopathology in
Parkinson's disease. Parkinsonism Relat Disord. 2009;15(5):379-82. doi:10.1016/j.parkreldis.2008.09.003

7. Ickenstein GW, Ambach H, Klöditz A, Koch H, Isenmann S, Reichmann $\mathrm{H}$ et al. Static Posturography in aging and Parkinson's disease. Front Aging neurosci. 2012;4:20. doi:10.3389/fnagi.2012.00020.

8. Lee JM, Koh SB, Chae SW, Seo WK, Kwon Y, Kim JH et al. Postural instability and cognitive dysfunction in early Parkinson's disease. Can J Neurol Sci. 2012;39(4):473-82. doi:10.1017/S0317167100013986

9. Stefani A, Lozano A, Peppe A, Stanzione P, Galati S, Tropepi D et al. Bilateral deep brain stimulation of the pedunculopontine and subthalamic nuclei in severe Parkinson's disease. Brain. 2007;130(6):1596-607. doi:10.1093/brain/awl346

10. Frenklach A, Luie S, Koop MM, Bronte-Stewart H. Excessive postural sway and the risk of falls at different stages of Parkinson's disease. Mov Disord. 2009;24(3):377-85. doi:10.1002/mds.22358

11. Liu-Ambrose TY, Ashe MC, Graf P, Beattie BL, Khan KM. Increased risk of falling in older community-dwelling women with mild cognitive impairment. Phys Ther. 2008;88(12):1482-91. doi:10.2522/ptj.20080117 
12. Souza CO, Voos MC, Francato DV, Chien HF, Barbosa ER. Influence of educational status on executive function and functional balance in individuals with Parkinson disease. Cogn Behav Neurol. 2013;26(1):6-13. doi:10.1097/WNN.0b013e31828c5956

13. Rocchi L, Chiari L, Cappello A, Horak FB. Identification of distinct characteristics of postural sway in Parkinson's disease: a feature selection procedure based on principal component analysis. Neurosci Lett. 2006;394(2):140-5. doi:10.1016/j.neulet.2005.10.020

14. Johnson L, James I, Rodrigues J, Stell R, Thickbroom G, Mastaglia F. Clinical and posturographic correlates of falling in Parkinson's disease. Mov Disord. 2013;28(9):1250-6. doi:10.1002/mds.25449

15. Voos MC, Pinheiro GB, Cicca LO, Lázaro A, Valle LER, Piemonte MEP. Os componentes motor e visual de uma tarefa-dupla devem ser associados ou isolados durante o treinamento? Fisioter Pesq. 2008;15(1):33-9. doi:10.1590/S1809-29502008000100006

16. Iersel MB, Kessels RPC, Bloem BR, Verbeek ALM, Rikkert MGMO. Executive functions are associated with gait and balance in community-living elderly people. J Gerontol A Biol Sci Med Sci. 2008;63(12):1344-9. doi:10.1093/gerona/63.12.1344

17. Stegemöller EL, Wilson JP, Hazamy A, Shelley MC, Okun MS, Altmann $L J$ et al. Associations between cognitive and gait performance during single- and dual-task walking in people with Parkinson Disease. Phys Ther. 2014;94(6):757-66. doi:10.2522/ptj.20130251

18. Ebersbach G, Gunkel M. Posturography reflects clinical imbalance in Parkinson's disease. Mov Disord. 2011;26(2):241-6. doi:10.1002/mds.23189

19. Brucki SMD, Nitrini R, Caramelli P, et al. Sugestões para o uso do mini-exame do estado mental no Brasil. Arq Neuropsiquiatr. 2003;61(3B):777-81. doi:10.1590/S0004-282X2003000500014

20. Metman LV, Myre B, Verney N, Hassin-Baer S, Arzbaecher J, Sierens $D$ et al. Test-retest reliability of UPDRS- III, dyskinesia scales, and timed motor test in patients with advanced Parkinson's disease: an argument against multiple baseline assessments. Mov Disord. 2004;19(9):1079-84. doi:10.1002/mds.20101

21. Hoehn MM, Yahr MD. Parkinsonism: onset progression and mortality. Neurology. 1967;17(5):427-42. doi:10.1212/WNL.17.5.427

22. Brucki SM, Rocha MS. Category fluency test: effects of age, gender and education on total scores, clustering and switching in Brazilian Portuguese-speaking subjects. Braz J Med Biol Res. 2004;37(12):1771-7. doi:10.1590/S0100-879X2004001200002

23. Qutubuddin AA, Pegg PO, Cifu DX, Brown R, McNamee S, Carne W. Validating the Berg Balance Scale for patients with Parkinson's disease: a key to rehabilitation evaluation. Arch Phys Med Rehabil. 2005;86(4):789-92. doi:10.1016/j.apmr.2004.11.005

24. Godi M, Franchignoni F, Caligari M, Giordano A, Turcato AM, Nardone A. Comparison of reliability, validity, and responsiveness of the miniBESTest and Berg Balance Scale in patients with balance disorders. Phys Ther. 2013;93(2):158-67. doi:10.2522/ptj.20120171

25. Shumway-Cook A, Woollacott MH. Motor control: theory and practical applications. 2nd ed. Philadelphia, PA: Lippincott Williams and Wilkins; 2001.

26. Azulay JP, Mesure S, Amblard B, Blin O, Sangla I, Pouget J. Visual control of locomotion in Parkinson's disease. Brain. 1999;122(1):111-20. doi:1093/brain/122.1.111

27. Rossi M, Soto A, Santos S, Sesar A, Labella T. A prospective study of alterations in balance among patients with Parkinson's Disease. Eur Neurol. 2009;61(3):171-76. doi:0.1159/000189270

28. Brown LA, Cooper SA, Doan JB, Dickin DC, Whishaw IQ, Pellis SM et al. Parkinsonian deficits in sensory integration for postural control: temporal response to changes in visual input. Parkinsonism Relat Disord. 2006;12(6):376-81. doi:10.1016/j.parkreldis.2006.03.004 